\title{
Coccidioidomycosis: Epidemiology, Fungal Pathogenesis, and Therapeutic Development
}

\author{
Hazael Hernandez ${ }^{1}$ • Victor H. Erives ${ }^{1} \cdot$ Luis R. Martinez $^{1}$
}

(C) Springer Nature Switzerland AG 2019

\begin{abstract}
Purpose of Review Coccidioidomycosis can result from the inhalation of infectious spores of Coccidioides species (spp.) immitis or posadasii. Clinical manifestations range from mild flu-like disease to severe disseminated infection that can require life-long therapy. Burden of this mycosis is high in the southwest region of the USA where it is well characterized, and in many areas of Mexico and Latin America where it is inadequately characterized. Here, we provide historical data and current knowledge on Coccidioides spp. pathogenesis as well as recent progress in therapeutic and vaccine development against coccidioidomycosis. Recent Findings The virulence mechanisms of Coccidioides spp. are largely unknown; however, production and regulation of a spherule glycoprotein, ammonium production, and melanization have all been proposed as integral factors in Coccidioides spp.' pathogenesis. Therapeutic options are limited and not $100 \%$ effective, but individualized treatment with triazoles or amphotericin $\mathrm{B}$ over the course of pulmonary or disseminated infection can be effective in resolution of coccidioidomycosis. Human immunization has not been achieved but efforts are ongoing.

Summary Advances in therapeutic and vaccine development are imperative for the prevention and treatment of coccidioidomycosis, especially for those individuals at risk either living or traveling to or from endemic areas.
\end{abstract}

Keywords Antifungals $\cdot$ Coccidioidomycosis $\cdot$ Epidemiology $\cdot$ Vaccine $\cdot$ Valley fever $\cdot$ Virulence

\section{Introduction}

Coccidioides species (spp.) are dimorphic fungi, which are present in the environment and can infect and cause disease in humans when arthroconidial spores are inhaled [1]. Coccidioides spp. are endemic in the southwest region of the United States (U.S.) and in other semiarid areas in Mexico and Latin America. Disease due to the progression of coccidioidal infection is termed coccidioidomycosis and two species have thus far been identified as etiologies: C. posadasii [2] and C. immitis [3, 4], the former having been identified more than 100 years after the initial discovery of the fungus [5]. While the two species are genetically different and there may exist

This article is part of the Topical Collection on Tropical Mycoses

Luis R. Martinez

lmartinez43@utep.edu

1 Department of Biological Sciences, The Border Biomedical Research Center, The University of Texas at El Paso, $500 \mathrm{~W}$. University Ave., Bioscience Research Building, Room 2.170, El Paso, TX 79968-9991, USA clinically distinct characteristics due to infection that are yet to be identified, no difference in disease progression, diagnosis, or treatment has been established. In fact, pathogenicity of the two species has been proposed to be comparable [6,7]. Infection with Coccidioides spp. commonly remains asymptomatic, but oftentimes presents as pneumonia that can be self-resolving and, in certain cases, life-threatening disseminated mycoses [8]. The public health impact of coccidioidomycosis is significant, with approximately 25,000 reported coccidioidomycosisassociated hospitalizations and over \$2 billion USD in hospital charges in California alone during 2000-2011 [9].

Infection due to Coccidioides spp. was first described in Argentina in 1892 by a native doctor who was examining skin lesions on a soldier [5] and shortly after in the U.S. during an examination of a manual laborer from the San Joaquin Valley in California [3] (Fig. 1). After mischaracterization of the etiological agent as a protozoan in 1896 [3], correct taxonomic status of Coccidioides as a fungus was established from 1900 's animal work involving the inoculation of guinea pigs and rabbits with the coccidioidal arthroconidia which led to coccidioidomycosis and satisfied Koch's postulates [4]. Important insight into the understanding of coccidioidomycosis 


\section{HISTORICAL TIMELINE OF COCCIDIOIDOMYCOSIS}

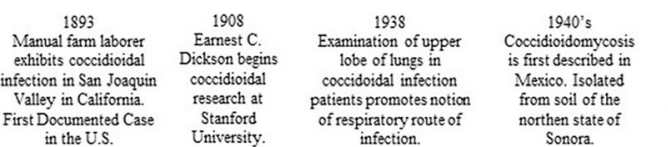

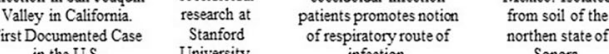
in the U.S.

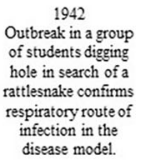

1960

First documented is confirmed in the

Motagua Valley.

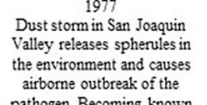
airborne outbreak: of the pathogen. Becoming known as "Valley Fever."

$1890 \quad 1950$

$1892 \quad 1896$

Doctor examines Emmet Risford
skin lesions on

Argentinian credited for

$\begin{array}{ll}\text { Argentinian } & \text { credted for } \\ \text { soldier. First classifying } & \text { Coccidioides }\end{array}$

documented case Coccidioides
in the world.
D. Chope accidently inhales

Coccidioides spores from

culture plate. Leading to his
mentor Ernest C. Dickson to

mentor Ernest C. Dickson to

for the fungus.
fole skin tesing me

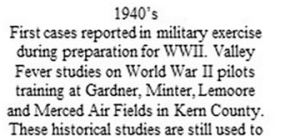

during preparation for WWII. Valley

raining at Gardner, Minter, Lemoor

and Merced Air Fields in Kern County.
These historical studies are still used to

determine and describe the naturas

course of and describe the natur

1951
irst teported human
case in Honduras is
confirmed in truck-
driver. Establishing
presence of the
disease in the region.

1965

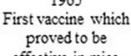

proved to be
effective in mice

effective in mice
infected with Coccidiodes was $\begin{array}{cc}1980 & 1998 \\ \text { First vaccine trial in Kern County } & \end{array}$

Californis plays a pivotal role in incidencest Cursuing a racine for Valley Fever. The coccidiodomycosis Cocci Clinic at Kern Medical Center is is reported in the blished. The clinic serves as one of U.S. the sites that tests the vaccine.

\section{8}

Coccidiodomycosis
is first reported in

Brazil.

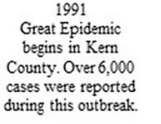
2016 $\$ 29$ hospitalizations due to cases of coccidioidomycosis in Brazil and becomes th highest statistic of America.

Fig. 1 Historical timeline of coccidioidomycosis

as an environmentally acquired infection developed from an incident in 1929 where a Stanford medical student accidentally inhaled Coccidioides spores from a culture plate and developed non-lethal pneumonia [10•]. This case led to a series of seminal findings over the next two decades by Ernest Dickson which, through the use of coccidioidin skin testing methods, robustly established the link between dust exposure, Coccidioides infection, and the emerging "valley fever" ("San Joaquin fever" or "desert fever") in Kern County, California [10•]. Further evidence that supported the proposed respiratory route for infection came from a Coccidioides outbreak in a group of students that had dug a hole in search of a rattlesnake in 1942 [11] and from previous descriptions in 1938 of lung upper lobe pneumonia case caused by coccidioidal lung infection [12]. Since then, the relationship of environmental disturbances and the infectious potential of Coccidioides spp. has been established and prophylactic and therapeutic solutions are actively being investigated.

In this review, we discuss Coccidioides spp. infection and its prevalence, highlighting risk factors and susceptible populations in under-resourced areas. Furthermore, coccidioidal virulence factors along with the current state of vaccination are examined, along with therapeutic strategies in development that hold promise for future treatment. We aim to inform on this neglected medically important fungi while we highlight the necessity for clinician awareness of coccidioidomycosis as a differential diagnosis in endemic areas or for cases involving individuals with recent travel to or from endemic areas.

\section{Coccidioidomycosis: the Desert Dust Disease of the Americas}

Coccidioides spp. exclusively inhabit the western hemisphere as thermally dimorphic microorganisms that can exist in saprotrophic or parasitic growth phases in the environment and in suitable hosts, respectively [13•]. The fungus grows saprotrophically as a mycelium consisting of filamentous hypha networks in soils of semiarid regions such as in the U.S. Southwest or in certain regions of Mexico and Latin America. Maturation of mycelia leads to the formation of single-cell barrel-shaped arthroconidia (spores) that are easily aerosolized by any form of soil disturbance, either natural or anthropogenic. The infectious arthroconidia can then be acquired through respiration and this has been described in many host organisms such as humans and in domesticated animals like dogs, cats, and livestock or alpacas $[14,15]$. In non-human primates, exposure to as few as 10-50 arthroconidial spores has been shown to cause disease in 4-6 weeks [16, 17]. Many investigations that challenge animals with arthroconidia use challenge load numbers with a similar order of magnitude. Once inhaled into the warm lungs of a host, arthroconidia initiate the thermal transition to spherules, thus initiating the infectious parasitic phase of the fungus. In vitro, this transition has been demonstrated at $37{ }^{\circ} \mathrm{C}$ and $10-14 \%$ atmospheric $\mathrm{CO}_{2}$ in chemically defined media [18] and contact with leukocytes has also been suggested as a stimulant for phase transition in the lungs [19]. The spherules then mature and proceed into the endosporulation stage where they swell into structures with diameters upwards of $100 \mu \mathrm{m}$ that contain 100-300 single-celled endospores which release upon rupture [13•]. Endospores mature into large second-generation endospore-filled spherules that endosporulate and burst, thereby repeating the fungal parasitic life cycle.

In $60-65 \%$ of individuals, acquisition of Coccidioides spp. leads to asymptomatic sub-clinical infection. Because acquisition of the fungus happens almost exclusively through the respiratory route, individuals with progression to more severe coccidioidomycosis present with symptoms characteristic of typical pneumonia or influenza such as fever, night sweats, 
myalgia, arthralgia, headache, fever, cough, and dyspnea which can develop 1-4 weeks after exposure [20]. Particularly in California, presentation of multiple symptoms is commonly referred to as the "valley fever." Coccidioides spp. are responsible for 17-29\% of community acquired pneumonia in endemic regions [21] and many have stressed the importance of its strong consideration as a differential diagnosis in endemic areas [22, 23*0]. Disseminated coccidioidomycosis occurs secondary to primary pneumonia in approximately $<5 \%$ of individuals infected [24] and coccidioidal meningitis is the most serious form of systemic disease [25]. Disseminated infection is typically treated with administration of amphotericin B or azole antifungals [26]. In addition, dissemination can result in cutaneous coccidioidomycosis secondary to acute infection whose manifestations mimic that of dermatologic diseases [27]. In very rare cases, primary cutaneous coccidioidomycosis can result after acquisition of fungal spores through exposed skin, although only about 30 of these cases have been reported since 1926 [27-29] making this the least common type of Coccidioides spp. infection manifestation [28]. For patients with primary cutaneous coccidioidomycosis, prognosis is excellent with proper treatment typically leading to complete resolution [28]. Skin rashes and arthritis can also result [24].

For populations in endemic regions, coccidioidomycosis is a fungal threat that warrants substantial notice yet it is regularly overlooked. Acute pulmonary coccidioidomycosis presents similar symptoms to other respiratory illnesses, resulting in many cases that are likely unnoticed or misdiagnosed $[23 \bullet \bullet]$. This is especially true in under-resourced communities or in populations with impaired access to medical care [23••]. Lack of state/nationwide skin or soil testing to determine the endemicity range and prevalence also participates in keeping the fungus' true threat potential in obscurity. Therefore, a concerted effort should be made by public health officials, community leaders, and clinicians in all endemic regions to increase awareness and preparedness in order to decrease the burden of this insidious disease.

\section{Coccidioidomycosis: Prevalence and the Impact on Public Health}

The ability of the arthroconidia to remain as viable infectious spores for years under dry conditions is a significant contributor to Coccidioides spp.' prevalence in endemic areas. Endemic regions all have similar environmental profiles and they have been characterized by their arid or semiarid climate, gentle winters, alkaline soil, and low precipitation [30•]. Environmental or anthropogenic disturbances can then aerosolize the resilient arthroconidia, and human hosts can acquire the spores through inhalation. Two Coccidioides spp. with variable geographical ranges cause infection, $C$. immitis and
C. posadasii. C. immitis is the predominant species in California and Baja California while $C$. posadasii predominates in the rest of the southwestern states. C. posadasii is also responsible for most, if not all recorded cases in Mexico and the rest of Latin America although there are sparse reports of C. immitis in locations like Venezuela, Argentina, and Colombia [23••, 31]. However, the possibility of $C$. immitis being endemic to those regions remain uncertain as the possibility of infection due to travel to and from endemic areas could not be excluded [23••]. Genetic analysis suggests that Coccidioides was introduced into South America from North America by mammals between 9000 and 140,000 years ago [32].

Dating back to the twentieth century, skin tests for the coccidioidal antigen coccidioidin have been used extensively to determine the endemic geographic ranges of the fungus in the environment $\left[10^{\bullet}, 13 \bullet\right]$. Areas surrounding established endemic regions are commonly designated as suspected endemic. In the U.S., many early studies using this method established Arizona and the central valley in California as the most endemic regions and endemicity has now also been established in Utah, Nevada, New Mexico, and Texas where the fungus is becoming an emerging threat. Similar skin testing surveys have been conducted in Latin America to establish the fungus' geographic range. However, most regions with or without endemic Coccidioides spp. lack internal comprehensive investigations and surveys that would establish clear geographical boundaries for the fungus. Thus, the extent to which the fungus is present in the environment of the Americas remains highly speculative. To date, one region with thousands of new yearly cases of autochthonous coccidioidomycosis remains the most thoroughly characterized: the U.S. Southwest.

\section{Coccidioides in the U.S. Southwest}

With over a quarter of the U.S. population inhabiting the mainland Southwest, disease from fungal etiologies endemic to the region should not be overlooked, especially Coccidioides spp. Morbidity due to coccidioidomycosis in hospitalized patients in the U.S. Southwest is significant, resulting in loss of income and a potentially altered quality of life. In California, one estimate places the average lifetime medical costs associated with treatment at $\$ 57,000$ USD per patient across all disease manifestations [33••]. Patients with uncomplicated pneumonia incur $\sim \$ 22,000$ USD lifetime costs, while those with diffuse/chronic pneumonia incur $\sim$ \$132,000 and individuals with disseminated disease including meningitis incur over $\$ 1,000,000$ USD [33••]. Moreover, about $75 \%$ of symptomatic patients miss work or school [34] for nearly a week when manifestation is uncomplicated pneumonia [33••]. In patients, with disseminated coccidioidomycosis, $10 \%$ of individuals have permanent work loss, while the remaining $90 \%$ lose an average of 90 work days [33••]. In 
California, coccidioidomycosis has emerged as a significant fungal threat in the past few decades with $75 \%$ of the state's cases occurring in the San Joaquin Central Valley [35]. From 1998 to 2011, documented cases steadily increased by about $13-16 \%$ each passing year, culminating in almost a $1000 \%$ increase of reported cases, up from 2271 in 1998 to 22,641 in 2011. The incidence of coccidioidomycosis attenuated to 8232 cases in 2014 but increased since then to 14,364 cases in 2017 [36]. While valley fever gets its name from California, the burden of coccidioidomycosis has historically been highest in Arizona, where approximately two-thirds of all infections were reported up until 2015 [36]. In 2016, only about $51 \%$ of cases were reported from Arizona and, in 2017, more cases were reported in California than in Arizona, ending the trend of Arizona having higher incidence for coccidioidomycosis [36]. In total, 14,364 cases were reported in 2017 making it the year with the fourth highest incidence since 1998 [36]. The severe threat that re-emerging coccidioidomycosis poses is being responded to by the National Institutes of Health (NIH). Recently, the NIH posted funding opportunity announcements in support of research activities contributing to the understanding of coccidioidomycosis [37].

Interestingly, natural disasters have been shown to affect the environmental release of fungal spores [38, 39]. Coccidioidomycosis has been associated with a few instances of post-disaster infection. In 1994, a magnitude 6.7 earthquake struck Northridge, California. In conjunction with secondary seismic activity, dust clouds were formed that were strongly implicated in contributing to an increase in aerosolized C. immitis spherules in the environment resulting in 203 cases of coccidioidomycosis in Ventura County, CA [40]. A similar airborne outbreak occurred previously in 1977 in the San Joaquin Valley [41] when a dust storm was implicated in 115 valley fever cases including 16 disseminated cases in non-endemic Sacramento county, 18 cases at a U.S. Navy air station in Kings County [42], and 117 more cases in Kern county than the previous year during the months counted [43], as well as many others across other Californian counties [38]. Worryingly, dust storm activity has intensified over the past few decades and the frequency of dust storms has been found to be correlated with valley fever cases [44].

Just as dust storms in California left an increase of coccidioidomycosis cases in its wake, it has been suggested that incidence of infection in Arizona can be predicted by other natural processes such as seasonal precipitation [45]. Human disturbance of soil through industry has also been suggested to possibly increase Coccidioides infectious potential [46]. Similarly, coccidioidomycosis cases have been reported after military exercises [10•] and construction projects [47]. Climate change has also been proposed as a driver of fungal proliferation in the environment and expansion of the endemic range of Coccidioides spp. [48] and the influence of climate change on valley fever is being increasingly analyzed [49]. In order to develop an appropriate public health system response, anthropogenic disturbances of soil caused by construction or climate change that affect the incidence of fungal disease like valley fever should continue to be investigated thoroughly.

In all southwestern states, there are areas purported to be highly endemic, established endemic, or both. However, many surrounding areas to the endemic states are also suspected to be endemic and should not be ruled completely safe, especially for those individuals with higher risk for infection. In fact, recently, the fungus has been identified in soil in Oregon [50] and cases have been reported as far north as Washington State in the Northwest of the U.S. [51]. Moreover, valley fever has been diagnosed in workers at Dinosaur National Monument [52] which spans the northeastern reaches of Utah and extends into Colorado. This and other cases may indicate that the endemic range for this fungus is increasing. It is suspected that pathogenic coccidioidal spores are found in the soils of many arid areas throughout North America, and their spread to new areas should be considered in the future. The overall increase of coccidioidomycosis in the southwest is troubling, and while the reason(s) have not been fully elucidated, Coccidioides spp. are emerging as a significant fungal threat to public health.

\section{Coccidioides in Latin America}

Coccidioidomycosis is of particular importance in Latin America due the large amount of individuals involved in agriculture and thus potentially at higher risk of exposure to aerosolized fungi [23]. In addition, significant segments of the population are medically underserved and resources for detection and/or treatment of coccidioidomycosis can be scarce or unavailable leading to high burden of disease. Likewise, clinical and epidemiologic data can be sparse $[23 \bullet \cdot, 31]$, which can result in underrepresentation of coccidioidal burden and potential unpreparedness for future infections. C. posadasii remains the most prevalent coccidioidal species in Mexico and the rest of Latin America $[23 \bullet \bullet, 53]$. In Mexico, coccidioidomycosis was first described in the mid-1940s $[54,55]$ and later isolated from soil in the northern state of Sonora [56]. Skin surveys during this time established endemicity in areas with soil profiles similar to soil in the U.S. Southwest [23••]. Therefore, much of the Mexican research focus has been on northern states with deserts, which lie directly across the border from endemic regions in the U.S. such as the states of Baja California, Sonora, Chihuahua, Coahuila, and Nuevo Leon [57-59]. In Latin America, Mexico has the highest incidence of coccidioidomycosis where it is known to be as prevalent as in endemic regions in the U.S. [60]. The current burden of coccidioidomycosis in Mexico is unknown; however, up until its dismissal as a reportable disease in 1994, an average of 1500 cases were reported yearly $[23 \bullet \bullet]$. For example, in a study involving 
668 individuals from rural and urban communities in Coahuila, skin tests revealed that $93 \%$ of individuals were positive to coccidioidin [58,61].

In Central America, Coccidioides spp. are also characteristically endemic in arid and semiarid regions of Honduras and Guatemala $[2,23 \bullet \bullet]$. Two early skin studies in Guatemala and Panama in 1945 and 1950, respectively, indicated less than $1 \%$ positive reactivity to coccidioidin in tested individuals $[62,63]$. In 1951, coccidioidomycosis in a truck driver from Honduras was described, becoming the first such case in the region and thereby establishing its presence in Honduras [64]. In Guatemala, the first human case was reported in 1960 [65, 66] and the fungus' endemicity was established in the Motagua Valley in western Guatemala based on evidence from an investigation on 6 individuals with the disease. This observation was supported by further findings from skin tests performed on $\sim 10,000$ individuals from the valley in the late 1960s [67].

In South America, coccidioidomycosis is also not reportable and studies are limited making the true incidence uncertain. Reported cases and skin test surveys that have been conducted in Colombia, Venezuela, Brazil, Paraguay, Bolivia, and Argentina are reviewed in detail [23••] with infection rates ranging from 2 to $46 \%$. Five cases have been reported in Colombia from 1958 to 2015 and 114 in Venezuela from 1948 to 2004 [23••]. In Brazil, coccidioidomycosis was first reported in 1978 and studies have been conducted on incidence in specific states since then $[31,68]$. In 2016, the nation's burden of coccidioidal disease was carefully elucidated and 829 hospitalizations due to coccidioidomycosis were described [69], making Brazil the South American country with the highest reported number of cases. However, this statistic might be misleading and indicative of underreported coccidioidomycosis in other South American countries rather than a greater disease burden in Brazil. Mycology is an extensively studied field in Brazil, and the nation is host to many excellent fungal investigators and clinicians, and this might account for the greater number of reports coming from the country. Ultimately, just like in the U.S., Coccidioides spp. are likely to be found in many areas that are yet to be described in scientific literature and it is probable that they might also be expanding into neighboring regions. A concerted effort by health officials in nations with reported cases might lead to a better understanding of coccidioidomycosis' impact on Latin America.

\section{Risk Factors for the Acquisition of Coccidioidomycosis}

Since Coccidioides spp. and their intimate association with the environment began to be characterized in the twentieth century, much knowledge has been acquired about related risks for infection with the fungus due to environmental exposure [30•]. Unfortunately, significant insight has been gathered directly from outbreaks in individuals exposed to dust in endemic regions. For example, it is now known that there are very high rates of exposure and coccidioidomycosis among incarcerated individuals in prisons, especially in California [70, 71]. While officials have made an effort to address the issue, one study found that health costs due to Coccidioides infection in California prisons were approximately \$23 million USD from 2006 to 2010 [72]. Individuals participating in outdoor activities such as hunting, sports, or construction are also at higher risk for infection [47, 73-75]. Furthermore, many outbreaks have arisen as a result of military exercises with some of the first cases reported in the 1940s during military exercises when troops were preparing for overseas battle in World War II [10•, 76].

The increase in globalization and fast travel is also an important consideration as patients might present with coccidioidomycosis in a non-endemic area after travel to an endemic area [77-79]. In fact, the incidence of reported cases in the U.S. outside of recognized endemic zones has increased in the past few decades [77, 80-83]. In Canada, a high number of reported cases in Ontario have even prompted reviews that investigate the impact of fungi on the city [84]. Outside of the western hemisphere, coccidioidomycosis has been observed in recent travelers of endemic zones returning home to Europe [85-87], Australia [88-90], and Asia [91-94]. The threat of coccidioidomycosis is thus a very important consideration for traveling individuals with a propensity for coccidioidal infection, such as immunocompromised individuals. Recent travelers to endemic areas that acquire coccidioidomycosis with more serious manifestations require medical assistance in their areas of residence and it is up to health care providers to be alert for coccidioidomycosis in the differential diagnosis, particularly in the setting of a pneumonia or other invasive infection non-responsive to antibacterial agents.

Gender is a determinant of risk to acquire coccidioidomycosis with men having higher rates of infection and dissemination [30•]. Although coccidioidomycosis occurs in all age groups, adults aged 40 and older have demonstrated a higher incidence for the disease [30•]. Moreover, an increased rate of dissemination has been described in non-Caucasian groups such as Hispanics, African Americans, and especially Filipinos [43, 76, 95]. Furthermore, American Indians and Alaskan Natives experience high coccidioidomycosisassociated hospitalization rates and high morbidity [96]. Medical status of individuals also plays a role, with pregnancy, diabetes, and cardiopulmonary disease being associated with infection and at least pregnancy with disease severity. Immunocompromised individuals are recognized to be at greater risk for an opportunistic infection by Coccidioides. In patients with HIV/AIDS, diminished $\mathrm{CD}^{+} \mathrm{T}$ cell counts is the greatest risk determinant, as there is an inverse 
correlation between the risk for disseminated coccidioidomycosis and total $\mathrm{CD}^{+}$counts $[97,98]$. Organ transplant recipients $[30 \bullet, 99,100]$ and patients on immunosuppression with high-dose corticosteroid [30 ${ }^{\bullet}$ or receiving a TNF- $\alpha$ antagonist [101] are also at increased risk for coccidioidomycosis.

\section{Coccidioides spp. Virulence Factors}

Coccidioidal arthroconidia that are aerosolized through environmental or anthropogenic means initiate infection after inhalation by a host. Once in the host respiratory system, arthroconidia undergo the thermally induced switch to the pathogenic-"parasitic" phase of the fungus' life cycle. Fungal spherules begin isotropic growth and hundreds of endospores begin to differentiate within the large spherule. As coccidioidal spherules mature in these initial stages of pulmonary infection, a membranous layer termed the spherule outer wall (SOW) composed of polysaccharides, lipids, and proteins is shed from the spherule [102]. Isolated SOW from cultures of Coccidioides demonstrate high immunoreactivity to anticoccidioidal antibodies isolated from patients [103]. SOW glycoprotein (SOWgp) has been established as the immunodominant molecule within SOW fractions responsible for this in vitro reactivity and for eliciting a human immune response to coccidioidal infection $[104,105]$. A defining characteristic of SOWgp is that it contains proline/aspartate-rich motifs that tandemly repeat 3-6 times, depending on the clinical isolate [106*]. Concerted evolution of these tandem sequences has been proposed as a mechanism that could potentially enhance the fungi's ability to evade host immune responses [107]. Also, proline-rich regions (PRRs) have been proposed as key motifs in proteins that participate in the adhesion of many microorganisms to host tissues $[108,109]$. This has been demonstrated in fungi containing glycoproteins with PRRs such as in Colletotrichum lindemuthianum [105, 108] and Candida albicans [109] and in the bacterium Streptococcus mutans [110] which contains a cell surface adhesin with a PRR.

In vitro adherence assays performed to investigate recombinant SOWgp's role as putative adhesion have demonstrated the glycoproteins' ability to bind to mammalian extracellular matrix (ECM) components such as laminin, fibronectin, and collagen [105]. During inhalation and infection, these types of ligands might mediate adherence of the fungus to host respiratory tissues. In fact, in a SOWgp knockout strain of C. immitis, spherules display a $30-50 \%$ reduction in their ability to bind to fibronectin and laminin. Furthermore, in an experiment evaluating the effect of SOWgp gene deletion on mice survival, the mutant without SOWgp showed decreased virulence. Animals challenged intranasally with $C$. immitis with the SOWgp gene died after 21 days while mice infected with the $C$. immitis SOWgp knockout had significantly greater survival, with $58 \%$ of animals surviving beyond 40 days postinfection. SOWgp is an established antigen suggesting that the loss of virulence in the SOWgp C. immitis mutant might be attributable to the fungus' decreased ability to bind to host tissue or, alternatively, due to the loss of SOWgp as an antigen, which may influence a strong immune response by the host resulting in collateral tissue damage.

Expression of SOWgp has been shown to be cyclic: prevalent during early spherule development but significantly decreasing during endosporulation [105]. During preendosporulation, the maturing spherule releases copious amounts of antigenic SOWgp, making the fungus vulnerable to opsonization and phagocytosis by leukocytes. When the spherule bursts, spherule contents and endospores that are the appropriate size to be phagocytized are released, initiating an intense host inflammatory response. Studies have shown that the fungus combats this with the production of a metalloproteinase (Mep1) [111] that digests SOWgp, effectively enhancing the endospores' ability to evade opsonization and subsequent phagocytosis [112]. In mice immunized with SOWgp, high antibody titers were observed and survival after challenge with mepl knockout arthroconidia significantly increased compared to immunized mice challenged with wildtype arthroconidia. Moreover, in vitro exposure of spherules (devoid of SOWgp after stripping by the action of purified Mep1) to alveolar macrophages resulted in enhanced phagocytosis and killing of the fungus.

Like in the medically relevant Cryptococcus spp., coccidioidal release of ammonia during infection is also implicated in the virulence of this fungus $[113,114]$. Coccidioides spp. respond to $\mathrm{pH}$ changes in their environment. For example, when the fungus is grown in acidic cultures in either the saprobic or parasitic phase, the fungus responds by secretion of $\mathrm{NH}_{3} / \mathrm{NH}_{4}{ }^{+}$, resulting in an increase in the $\mathrm{pH}$ of the culture. The enzyme responsible for production of a large portion of cellular ammonia is urease $[115,116]$, which catalyzes the hydrolysis of urea into two ammonia molecules that neutralize acid by spontaneously protonating to form ammonium at physiological $\mathrm{pH}$ [117]. Ureases have been established as determinants of pathogenesis in other microorganisms [118] such as in Helicobacter pylori, which is able to use ureases to acclimatize to the acidic conditions of the gastric milieu [119]. These bacterial ureases have been implicated in exacerbated tissue damage by accumulation of ammonium in infected tissues [113]. A similar mechanism of damage has been proposed for Coccidioides spp. and studies have provided evidence corroborating this hypothesis [113, 120]. In one investigation, $55 \%$ of mice challenged with a $C$. posadasii strain lacking the urea gene survived beyond 50 days post challenge while a wild-type strain challenge resulted in $100 \%$ mortality by day 18 [113]. The ureidoglycolate hydrolase enzymatic pathway has been proposed as another source of coccidioidal ammonia [113]. In this study, a 
challenge in mice performed with a mutant strain in urea and ureidoglycolate hydrolase showed $90 \%$ survival after 30 days.

Coccidioides spp. also produce melanin-like pigments [121] similar to those observed in other medically relevant fungi such as Cryptococcus neoformans, Aspergillus spp., Exophiala dermatitidis, Sporothrix schenckii, Histoplasma capsulatum, Paracoccidioides brasiliensis, Scedosporium prolificans, and Blastomyces dermatitidis [122-126]. Melanization is a key contributor towards fungal virulence and environmental persistence with extensive studies demonstrating that this dark pigment on the cell wall protects fungi against extreme temperature, UV light, toxic metals, antimicrobial peptides, antifungals, and nitrogen/oxygen oxidants [127]. While the impact of melanization has been described in other fungi, further studies of Coccidioides spp. need to be conducted to further elucidate the extent to which melanization enhances coccidioidal environmental persistence and pathogenicity.

SOWgp production, SOWgp dysregulation by the action of Mep1, urease activity, and melanin production are four key means by which this fungus can adversely impact/damage infected hosts. Three of these virulence mechanisms and their concerted contribution to the overall virulence of Coccidioides spp. have been extensively reviewed [106•]. With the completion of Coccidioides spp. sequencing projects and the advent of newer genetic manipulation techniques, there surely is promise that novel virulence mechanisms of this pathogen will be elucidated aiding in the development of prophylactic and therapeutic strategies to combat coccidioidomycosis.

\section{Therapeutic Approaches to Fight Coccidioidomycosis}

As with other fungi, there is currently no therapy that results in resolution of coccidioidomycosis in all cases. Patients with coccidioidomycosis that proceeds to a more severe form are typically burdened with high morbidity and often mortality. Antifungal therapy is expensive and hospital costs can quickly accumulate especially if intensive care is needed. Therefore, it is imperative to find the most effective treatment with minimal acquired damage to tissues and organs. The majority of patients that become infected with Coccidioides spp. remain asymptomatic or infection only leads to a mild manifestation. Thus, primary coccidioidal pneumonia in immunocompetent individuals will usually resolve without medical intervention or administration of antifungal therapy [26]. In fact, studies of antifungal administration during early pulmonary infection show no evidence in support of such treatments [26, 128, 129]. In addition, no randomized clinical studies exist that justify early therapy in healthy hosts [26, 130]. In fact, practice guidelines have suggested that treatment of early primary coccidioidomycosis should be highly individualized $[26,131]$. For example, in immunocompetent patients, azole therapy might not be necessary; however, periodic reassessment might be appropriate to ensure resolution of mycosis or identify complications. In patients with an overt pulmonary manifestation, biopsy or radiological examination might be performed to rule out malignancy. In patients with hydrocephalus due to disseminated meningeal mycoses, surgical implementation of a shunt may be required [26]. However, these medical devices are at extremely high risk for infection and clogging, which can exacerbate morbidity. In pregnant mothers, alternative therapies might be pursued due to the possible teratogenicity of azoles. Nevertheless, recent findings have determined that this might only be the case in the first trimester of pregnancy and, even then, low doses during first trimester might be an option [132]. Thus, administration of azoles might be appropriate during second and third trimesters, if so determined by a clinician $[26,131]$. Initiation of antifungal therapy has proven to be effective in many cases, but there is no guarantee that infection will not return after discontinuation. Thus, antifungal therapy is often indefinite and lifelong, especially for more advanced coccidioidomycosis $[26,131,133]$.

The pharmacology and treatment of coccidioidomycosis has been excellently reviewed [134••]. Like in the treatment of other fungal infections, triazole antifungal drugs (fluconazole, itraconazole, voriconazole, and posaconazole) and amphotericin $\mathrm{B}$ are the agents administered to counter coccidioidal infections [134 •.]. Triazoles are largely fungistatic and they exert their effect through inhibition of the ergosterol synthesis pathway in fungi which leads to destabilization of membrane-associated enzymes and eventual inhibition of fungal growth. Fluconazole is the most commonly administered antifungal drug for treatment of coccidioidomycosis as it is relatively inexpensive and available in intravenous or oral preparations [134••]. The drug has excellent oral bioavailability and it is unaltered by food or gastric conditions. Furthermore, fluconazole is not protein bound and distributes widely into most body tissues and fluids such as the central nervous system (CNS) $[135,136]$. This is especially useful for the treatment of disseminated coccidioidomycosis in the CNS. In vitro, fluconazole exhibits higher minimal inhibitory concentrations (MICs) in Coccidioides spp. compared to other azoles [137]; however, this has not been rigorously corroborated in patients [134••]. Itraconazole is also commonly administered [134.•] and some evidence has shown that its use is superior in the treatment of some disseminated forms of coccidioidomycosis [138]. Reduced relapse rates after discontinuation of therapy with itraconazole compared to fluconazole have also been observed. Itraconazole is available in capsule and oral solution formulations, as well as intravenously in some countries outside of the U.S., and the different forms of the drug exhibit differing bioavailability and dispersal in the body. After the development and introduction of fluconazole and itraconazole in the 1990s, there remained a need for second-generation triazoles to account for fluconazole's limited spectrum of antifungal activity and itraconazole's absorption limitations [139]. This led to the 
development of voriconazole and its approval by the U.S. Food and Drug Administration (FDA) in 2002. Voriconazole is a synthetic derivative of fluconazole which contains a fluorinated pyrimidine and an $\alpha$-methyl group and exhibits expanded activity. There is limited experience with the use of voriconazole in the treatment of coccidioidomycosis and the drug is used in patients who are intolerant or refractory to the other azoles [134••] and has been effective in such patients [140]. Voriconazole has also been used to successfully treat coccidioidal meningitis [140, 141]. Although voriconazole exhibits excellent bioavailability and distribution properties, it is also toxic [142, 143]. Posaconazole is another azole with limited clinical experience for coccidioidomycosis. It is available intravenously or by tablet. In animal models, the drug has been found to be the most active azole $[144,145]$ and the drug has also demonstrated superior sterilization in tissues in comparison to itraconazole. Large clinical trials with posaconazole have not been conducted, and thus far, no clinical benefit over other triazoles has been established [134••].

Amphotericin B, a polyene, is usually reserved for severe cases of coccidioidomycosis [26]. Amphotericin B binds irreversibly to ergosterol, resulting in disruption of fungal membrane integrity and ultimately cell death. Before the development of the triazoles, amphotericin B was the primary antifungal agent used in the treatment of coccidioidomycosis. With the advent of triazole treatment, amphotericin B is usually reserved as the final option in treatment, or for widely disseminated coccidioidomycosis [146] because the drug exhibits high toxicity due to off target binding to cholesterol in human cells. The drug has proven efficacy in some patients with disseminated coccidioidomycosis to the CNS when applied intravenously but it shows low penetration into the CNS.

All of the therapeutic options available for the treatment of coccidioidomycosis have positive and negative aspects regarding cost, bioavailability, tolerability, penetration, toxicity, and pharmacokinetic/pharmacodynamics characteristics. Therefore, as [134.•] points out, there is an existing need for therapeutics that improve on adverse characteristics of the currently available clinical options [134••]. Currently, there are several novel agents in preclinical development such as nanoparticle and cochleate formulations of amphotericin B [147], itraconazole formulations with enhanced absorption SUBAitraconazole [148], glucan synthase inhibitors [149], and chitinase inhibitor nikkomycin Z. Ultimately, the search is ongoing for agents to battle Coccidioides spp., and it is necessary due to the fungus' resurgence and infectious potential.

\section{State of Developing a Coccidioidal Vaccination}

Similar to other fungal etiologies, thus far, there is currently no vaccine for prophylactic immunization against Coccidioides spp. However, patients that recover from coccidioidomycosis typically acquire lifelong immunity, indicating that development of a vaccine that can achieve similar results is feasible. At the moment, we do not have a comprehensive understanding of coccidioidomycosis' pathogenesis, but great efforts have and are being made to identify strategies that can be used in the development of an effective vaccine. In the 1960s, the first vaccine which proved to be effective in mice infected with Coccidioides was formulated [150]. Mice were immunized with formalin-killed spherules (FKS) and this was later shown to reduce the severity of disease in a primate model. The vaccine eventually moved to double-blind phase III clinical trials, but its progress was stopped after the killed spherule vaccine did not demonstrate significant reduction of incidence or severity in the vaccinated group in humans and it induced an over reactive immune response [151]. In 2007 and 2009, another live-attenuated vaccine began to be investigated [152] when heat-killed Saccharomyces cerevisiae was reported to protect against aspergillosis and candidiasis, thus prompting investigation on the effect of the vaccine on coccidioidomycosis. It was ultimately determined that heat-killed $S$. cerevisiae conferred less protection than formalin-killed spherule vaccination and subcutaneous immunization with a fraction derived from mechanically derived spherules [153].

With the advent of more contemporary techniques and a more advanced understanding of immunology and Coccidioides spp.' genome, identification of potential antigens that can be recombinantly produced and used for immunization have also become the focus of investigations. Since then, a large number of candidate antigens have been discovered [154] and their efficacy after combination with adjuvants are also being evaluated. Furthermore, two live-attenuated vaccines have been isolated and evaluated in murine models. Both attenuated mutant strains used for the vaccine formulation were created by knocking out chitin-related genes that disable the microorganisms' ability to undergo transformation from its saprobic form to the parasitic or its ability to endosporulate within the lungs. To test whether the mutants lacked virulence, mice were infected with an extremely high dose of arthroconidia (5000 spores) that is orders of magnitude higher than that necessary for death. All the mice survived, enabling researchers to investigate their immunization potential [155]. For instance, mice immunized with 7500 arthroconidia had $100 \%$ survival after 75 days with a challenge with a lethal dose of non-attenuated arthroconidia. While these results are promising, severe hurdles with the FDA have to be overcome before these strains can be used in trials with humans. Further studies focusing on the immune responses generated by live-attenuated vaccination and safety issues associated with delivering live-attenuated coccidioidal strains particularly in immunocompromised individuals are necessary [156]. However, these findings provide a proof-ofconcept study that opens a novel area of research and a potential therapeutic strategy to prevent and reduce the devastating 
consequences of coccidioidomycosis, particularly in individuals living in endemic regions.

\section{Conclusion}

Coccidioidomycosis is an emerging threat to human health on two continents in the western hemisphere. While the burden of this disease might at times show patterns of attenuation, current infection trends indicate that the prevalence of coccidioidomycosis is increasing in magnitude and that the causative agent is evolving and expanding outside of historically endemic regions. In the southwest region of the U.S., coccidioidomycosis is an overt threat, as it affects local populations at epidemic levels. Many of the U.S. most populous cities are in the Southwest, which means that tens of millions of individuals that already reside there are potentially at risk. Moreover, the southwest population is increasing rapidly [157] and 6 out of the 10 fastest growing cities in the U.S. reside in this region. As many individuals migrate to the U.S. Southwest, there is coccidioidal risk to individuals without previous exposure to Coccidioides spp. Due to the increasing population density, there is also an associated increase in agricultural, commercial, and industrial projects being carried out, which only serves to exacerbate the propagation of Coccidioides spp. and thus their burden of disease. In Latin America, the threat of coccidioidomycosis is more insidious in nature as it is likely to be a far more significant threat than scientific or clinical records indicate. Socio-economic conditions and the current status of health care access in Latin American regions present significant challenges in the diagnosis and management of coccidioidomycosis.

In the past few decades and due to global climate change, evidence indicates that there has been an increase in natural disasters. Climactic phenomena such as dust storms, hurricanes, mudslides, unaccompanied high winds, and tornados are all drivers of aerosolization. An increase in events such as these should raise an increase in concern, especially since fungal outbreaks, particularly coccidioidomycosis, following a natural disaster have been observed in areas affected by such events. Although the threat of coccidioidomycosis is considerable, significant advances have been made in endeavors with a mission to ameliorate its burden. Investigations into Coccidioides spp. virulence and pathogenesis are rigorous and ongoing, and now there is special emphasis in drug and vaccine development for prevention and treatment of this neglected mycosis. Continuing support of these scientific endeavors and an increased effort for public education on the topic will surely result in decreased disease burden and an eventual resolution to coccidioidomycosis.

Acknowledgements The authors would like to thank Joshua D. Nosanchuk, M.D., for providing his review of the manuscript.
Funding Information H.H. was supported by National Institute of General Medical Sciences (NIGMS) RISE training grant R25 GM069621-15. L.R.M. was partially supported by the National Institute of General Medical Sciences of the U.S. National Institutes of Health (NIH) under award number 1R15GM117501-01A1. L.R.M. is partially funded and has an appointment in the Infectious Diseases and Immunology cluster of the Border Biomedical Research Center (BBRC; National Institute on Minority Health and Health Disparities award number 2G12MD007592), UTEP's Research Centers in Minority Institutions Program.

\section{Compliance with Ethical Standards}

Conflict of Interest The authors declare that they have no conflict of interest.

Human and Animal Rights and Informed Consent This article does not contain any studies with human or animal subjects performed by any of the authors.

\section{References}

Papers of particular interest, published recently, have been highlighted as:

- Of importance

•- Of major importance

1. Huppert M, Sun SH, Harrison JL. Morphogenesis throughout saprobic and parasitic cycles of Coccidioides immitis. Mycopathologia. 1982;78(2):107-22.

2. Fisher MC, Koenig GL, White TJ, Taylor JW. Molecular and phenotypic description of Coccidioides posadasii sp. nov., previously recognized as the non-California population of Coccidioides immitis. Mycologia. 2002;94(1):73-84.

3. Rixford E, Gilchrist TC. Two cases of protozoan (coccidioidal) infection of the skin and other organs. Johns Hopkins Hosp Rep. 1896;10:209-68.

4. Ophuls W. Further observations on a pathogenic mould formerly described as a protozoon (Coccidioides immitis, Coccidioides pyogenes). J Exp Med. 1905;6(4-6):443-85.

5. Posadas A. Un nuevo caso de micosis fungoidea con posrospemias. An Cir Med Argent. 1892;15:585-97.

6. Ampel NM, Hector RF. Measuring cellular immunity in coccidioidomycosis: the time is now. Mycopathologia. 2010;169(6):4256.

7. Whiston E, Zhang Wise H, Sharpton TJ, Jui G, Cole GT, Taylor JW. Comparative transcriptomics of the saprobic and parasitic growth phases in Coccidioides spp. PLoS One. 2012;7(7):e41034.

8. Galgiani JN, Ampel NM, Blair JE, Catanzaro A, Johnson RH, Stevens DA, et al. Coccidioidomycosis. Clin Infect Dis. 2005;41(9):1217-23.

9. Sondermeyer G, Lee L, Gilliss D, Tabnak F, Vugia D. Coccidioidomycosis-associated hospitalizations, California, USA, 2000-2011. Emerg Infect Dis. 2013;19(10):1590-7.

10. Hirschmann JV. The early history of coccidioidomycosis: 18921945. Clin Infect Dis. 2007;44(9):1202-7 This review describes the discovery and early characterization of Coccidioides spp. up until 1945 and highlights some of the key early Coccidioides sp. investigators like CE Smith and their contributions.

11. Davis BL, Smith RT, Smith CE. An epidemic of coccidioidal infection (coccidioidomycosis). JAMA. 1942;118:1182-6. 
12. Dickson EC. Coccidioides infection (coccidioidomycosis): II. The primary type of infection. Arch Intern Med. 1938;62(5):853-71.

13. Nguyen C, Barker BM, Hoover S, Nix DE, Ampel NM, Frelinger JA, et al. Recent advances in our understanding of the environmental, epidemiological, immunological, and clinical dimensions of coccidioidomycosis. Clin Microbiol Rev. 2013;26(3):505-25 This review summarizes many aspects of Coccidioides spp. such as their mycology, population genetics, epedemiology, clinical managements, and diagnostic testing.

14. Butkiewicz CD, Shubitz LF. Coccidioidomycosis in alpacas in the southwestern United States. Transbound Emerg Dis. 2019;66(2): $807-12$.

15. Graupmann-Kuzma A, et al. Coccidioidomycosis in dogs and cats: a review. J Am Anim Hosp Assoc. 2008;44(5):226-35.

16. Blundell GP, et al. The pathology of Coccidioides immitis in the Macaca mulatta. Am J Pathol. 1961;39:613-30.

17. Converse JL, et al. Pathogenesis of Coccidioides immitis in monkeys. J Bacteriol. 1962;83:871-8.

18. Converse JL. Effect of physico-chemical environment of spherulation of Coccidioides immitis in a chemically defined medium. J Bacteriol. 1956;72(6):784-92.

19. Galgiani JN, Hayden R, Payne CM. Leukocyte effects on the dimorphism of Coccidioides immitis. J Infect Dis. 1982;146(1): 56-63.

20. Hector RF, Rutherford GW, Tsang CA, Erhart LM, McCotter O, Anderson SM, et al. The public health impact of coccidioidomycosis in Arizona and California. Int J Environ Res Public Health. 2011;8(4):1150-73.

21. Sharma S, Thompson GR III. How I treat coccidioidomycosis. Curr Fungal Infect Rep. 2012;7:29-35.

22. Buhrow SM. Coccidioidomycosis: a differential diagnosis for visitors to the southwest. Am J Nurs. 2013;113(11):52-5.

23.• Laniado-Laborin R, et al. Coccidioidomycosis in Latin America. Med Mycol. 2019;57(Supplement_1):S46-55 This study reviews cases of coccidioidomycosis in Mexico, Central America, and South America and highlights molecular studies of Coccidioides spp. performed from with human, enviromental, and animal samples from Mexico.

24. Cox RA, Magee DM. Coccidioidomycosis: host response and vaccine development. Clin Microbiol Rev. 2004;17(4):804-39 table of contents.

25. Johnson R, Ho J, Fowler P, Heidari A. Coccidioidal meningitis: a review on diagnosis, treatment, and management of complications. Curr Neurol Neurosci Rep. 2018;18(4):19.

26. Ampel NM. The treatment of coccidioidomycosis. Rev Inst Med Trop Sao Paulo. 2015;57(Suppl 19):51-6.

27. Garcia Garcia SC, Salas Alanis JC, Flores MG, Gonzalez Gonzalez SE, Vera Cabrera L, Ocampo Candiani J. Coccidioidomycosis and the skin: a comprehensive review. An Bras Dermatol. 2015;90(5):610-9.

28. Chang A, et al. Primary cutaneous coccidioidomycosis. J Am Acad Dermatol. 2003;49(5):944-9.

29. Shiu J, Thai M, Elsensohn AN, Nguyen NQ, Lin KY, Cassarino DS. A case series of primary cutaneous coccidioidomycosis after a record-breaking rainy season. JAAD Case Rep. 2018;4(5):412-4.

30. Brown J, et al. Coccidioidomycosis: epidemiology. Clin Epidemiol. 2013;5:185-97 This review examines the history, ecology, and epidemiology of Coccidioides spp. and highlights risk factors such as age, gender, race, pregnancy, transplant, immunosuppression, and imprisonment in Southwest prisons.

31. Colombo AL, Tobón A, Restrepo A, Queiroz-Telles F, Nucci M. Epidemiology of endemic systemic fungal infections in Latin America. Med Mycol. 2011;49(8):785-98.

32. Fisher MC, Koenig GL, White TJ, San-Blas G, Negroni R, Alvarez IG, et al. Biogeographic range expansion into South
America by Coccidioides immitis mirrors New World patterns of human migration. Proc Natl Acad Sci U S A. 2001;98(8): 4558-62.

33.• Wilson L, et al. The rise of valley fever: prevalence and cost burden of coccidioidomycosis infection in California. Int $\mathrm{J}$ Environ Res Public Health. 2019;16(7) This study assesses the economics of the morbidity and mortality associated with coccidioidomycosis in California such as the costs resulting from uncomplicated pneumonia, chronic pneumonia, and disseminated disease.

34. Centers for Disease, C., Valley fever awareness (https://www.cdc. gov/features/valleyfever/index.html). 2019.

35. UC Davis information on valley fever (https://health.ucdavis.edu/ medmicro/cocci.html). 2019.

36. Centers for Disease, C., Valley fever (coccidioidomycosis) statistics (https://www.cdc.gov/fungal/diseases/coccidioidomycosis/ statistics.html). 2019.

37. NIH, U.S., Novel approaches to understand, prevent, treat, and diagnose coccidioidomycosis (valley fever) and other select endemic fungal infections (https://grants.nih.gov/grants/guide/pafiles/PA-19-082.html). 2018.

38. Benedict K, Park BJ. Invasive fungal infections after natural disasters. Emerg Infect Dis. 2014;20(3):349-55.

39. Hernandez H, Martinez LR. Relationship of environmental disturbances and the infectious potential of fungi. Microbiology. 2018;164(3):233-41.

40. Schneider E, Hajjeh RA, Spiegel RA, Jibson RW, Harp EL, Marshall GA, et al. A coccidioidomycosis outbreak following the Northridge, Calif, earthquake. JAMA. 1997;277(11):904-8.

41. Flynn NM, et al. An unusual outbreak of windborne coccidioidomycosis. N Engl J Med. 1979;301(7):358-61.

42. Williams PL, Sable DL, Mendez P, Smyth LT. Symptomatic coccidioidomycosis following a severe natural dust storm. An outbreak at the Naval Air Station, Lemoore, Calif. Chest. 1979;76(5): 566-70.

43. Pappagianis D, Einstein H. Tempest from Tehachapi takes toll or Coccidioides conveyed aloft and afar. West J Med. 1978;129(6): 527-30.

44. Tong DQ, Wang JXL, Gill TE, Lei H, Wang B. Intensified dust storm activity and valley fever infection in the southwestern United States. Geophys Res Lett. 2017;44(9):4304-12.

45. Tamerius JD, Comrie AC. Coccidioidomycosis incidence in Arizona predicted by seasonal precipitation. PLoS One. 2011;6(6):e21009.

46. Talamantes J, Behseta S, Zender CS. Fluctuations in climate and incidence of coccidioidomycosis in Kern County, California: a review. Ann N Y Acad Sci. 2007;1111:73-82.

47. Cummings KC, et al. Point-source outbreak of coccidioidomycosis in construction workers. Epidemiol Infect. 2010;138(4):50711.

48. Coates SJ, Fox LP. Disseminated coccidioidomycosis as a harbinger of climate change. JAAD Case Rep. 2018;4(5):424-5.

49. Weaver EA, Kolivras KN. Investigating the relationship between climate and valley fever (coccidioidomycosis). Ecohealth. 2018;15(4):840-52.

50. Hawryluk M., Traces of valley fever fungus found in Central Oregon (http://www.bendbulletin.com/home/4524652-151/ traces-of-valley-fever-fungus-found-in-central\%0D\%0A). The Bulletin, 2016

51. Marsden-Haug N, et al. Coccidioidomycosis acquired in Washington State. Clin Infect Dis. 2013;56(6):847-50.

52. Johnson SM, Carlson EL, Fisher FS, Pappagianis D. Demonstration of Coccidioides immitis and Coccidioides posadasii DNA in soil samples collected from Dinosaur National Monument, Utah. Med Mycol. 2014;52(6):610-7. 
53. Bialek R, Kern J, Herrmann T, Tijerina R, Cecenas L, Reischl U, et al. PCR assays for identification of Coccidioides posadasii based on the nucleotide sequence of the antigen 2/proline-rich antigen. J Clin Microbiol. 2004;42(2):778-83.

54. Madrid GS. Coccidioidomicosis, vol. 6: Prensa Medica; 1946. p. $1033-5$.

55. Madrid GS. Las micosis pulmonares. Rev Mex Tuber Ap Resp. 1948;9:32-55.

56. Sotomayor C, Madrid GS, Torres EA. Aislamiento de Coccidioides immitis del suelo de Hermosillo, Sonora México. Rev Latinoam Microbiol. 1960;3:237-8.

57. Baptista Rosas RC, Riquelme M. The epidemiology of coccidioidomycosis in Mexico. Rev Iberoam Micol. 2007;24(2):100-5.

58. Gonzalez-Benavides J. The panorama of coccidioidomycosis in Nuevo Leon from 1978 to 1988. Gac Med Mex. 1991;127(5): 427-32 discussion 432-3.

59. Laniado Laborin R, Moreno RPC, Cerro MA. Tijuana: endemic zone of Coccidioides immitis infection. Salud Publica Mex. 1991;33(3):235-9.

60. Ajello L. Comparative ecology of respiratory mycotic disease agents. Bacteriol Rev. 1967;31(1):6-24.

61. Mondragon-Gonzalez R, et al. Detection of Coccidioides immitis infection in Coahuila, Mexico. Rev Argent Microbiol. 2005;37(3): 135-8.

62. Tucker HA. Histoplasmin, tuberculin and coccidioidin sensitivity on the Isthmus of Panama; preliminary report of 500 patients. Am J Trop Med Hyg. 1950;30(6):865-70.

63. Andrade M. Investigation of coccidioidomycosis in Guatemala City, using the coccidioidin skin test. Doctoral thesis, Facultad de Medicina, Universidad de San Carlos de Guatemala, 1945.

64. Castro A, Trejos A. Confirmation of the first Central American case of coccidioidomycosis. Rev Med Costa Rica. 1951;10:89 90.

65. Perez-Guisasola E, Rosal JE. Human cocciodioidomycosis in Guatemala mycologic, histopatholocic diagnosis and biologic confirmation of the first case. Revista del Colegio Médico de Guatemala. 1960;XI:290-4.

66. Garcia Valdes A, Close de Leon J, Rivera LJ. Coccidioidomycosis communication of the first human case in Guatemala. Revista del Colegio Médico de Guatemala. 1960;XI:284-9.

67. Mayorga RP, Espinoza H. Coccidioidomycosis in Mexico and Central America. Mycopathol Mycol Appl. 1970;41(1):13-23.

68. Cordeiro Rde A, et al. Twelve years of coccidioidomycosis in Ceara State, Northeast Brazil: epidemiologic and diagnostic aspects. Diagn Microbiol Infect Dis. 2010;66(1):65-72.

69. Giacomazzi J, et al. The burden of serious human fungal infections in Brazil. Mycoses. 2016;59(3):145-50.

70. Burwell LA, Park BJ, Wannemuehler KA, Kendig N, Pelton J, Chaput E, et al. Outcomes among inmates treated for coccidioidomycosis at a correctional institution during a community outbreak, Kern County, California, 2004. Clin Infect Dis. 2009;49(11): e113-9.

71. Lee LA, Yuan J, Vugia D, Wheeler C, Chapnick R, MohleBoetani J. Increased coccidioidomycosis among inmates at a California prison: initial investigation in 2005 to 2006. J Correct Health Care. 2017;23(3):347-52.

72. Coccidioidomycosis in California's adult prisons 2006-2010. California Correctional Health Care Services Public Health Unit and Quality Management; 2012

73. Laniado-Laborin R. Expanding understanding of epidemiology of coccidioidomycosis in the Western hemisphere. Ann N Y Acad Sci. 2007;1111:19-34.

74. Stern NG, Galgiani JN. Coccidioidomycosis among scholarship athletes and other college students, Arizona, USA. Emerg Infect Dis. 2010;16(2):321-3.
75. Werner SB, Pappagianis D, Heindl I, Mickel A. An epidemic of coccidioidomycosis among archeology students in northern California. N Engl J Med. 1972;286(10):507-12.

76. Smith CE, Beard RR, et al. Varieties of coccidioidal infection in relation to the epidemiology and control of the diseases. Am J Public Health Nations Health. 1946;36(12):1394-402.

77. Diaz JH. Travel-related risk factors for coccidioidomycosis. J Travel Med. 2018;25(1).

78. Panackal AA, Hajjeh RA, Cetron MS, Warnock DW. Fungal infections among returning travelers. Clin Infect Dis. 2002;35(9): 1088-95.

79. Trimble A, Moffat V, Collins AM. Pulmonary infections in the returned traveller. Pneumonia (Nathan). 2017;9(1).

80. Centers for Disease, C. Coccidioidomycosis among persons attending the world championship of model airplane flying - Kern County, California, October 2001. MMWR Morb Mortal Wkly Rep. 2001, 50(49):1106-7.

81. Chaturvedi V, Ramani R, Gromadzki S, Rodeghier B, Chang HG, Morse DL. Coccidioidomycosis in New York State. Emerg Infect Dis. 2000;6(1):25-9.

82. Desai NR, et al. Coccidioidomycosis in nonendemic area: case series and review of literature. J La State Med Soc. 2010;162(2): 97-103.

83. Desai SA, et al. Coccidioidomycosis in non-endemic areas: a case series. Respir Med. 2001;95(4):305-9.

84. Brown EM, McTaggart LR, Dunn D, Pszczolko E, Tsui KG, Morris SK, et al. Epidemiology and geographic distribution of blastomycosis, histoplasmosis, and coccidioidomycosis, Ontario, Canada, 1990-2015. Emerg Infect Dis. 2018;24(7):1257-66.

85. Chandesris MO, et al. Coccidioidomycosis: an imported invasive fungal disease in France. Med Mal Infect. 2008;38(6):336-42.

86. Indhirajanti S, et al. Pulmonary coccidioidomycosis: import illness and the importance of travel history. Neth J Med. 2009;67(10): 353-5.

87. Pistone T, Lacombe K, Poirot JL, Girard PM, Meynard JL. Imported concomitant coccidioidomycosis and histoplasmosis in an HIV-infected Colombian migrant in France. Trans R Soc Trop Med Hyg. 2005;99(9):712-5.

88. Baird RW, Teichtahl H, Ednie HM, Tasiopoulos A, Ryan N, Gee D. A fluffy white traveller: imported Coccidiodes immitis infection in an Australian tourist. Pathology. 1999;31(1):47-50.

89. Subedi S, Broom J, Caffery M, Bint M, Sowden D. Coccidioidomycosis in returned Australian travellers. Intern Med J. 2012;42(8):940-3.

90. Symmers WS. An Australian case of coccidioidomycosis? Pathology. 1971;3(1):1-8.

91. Oberoi JK, Wattal C, Aggarwal PK, Khanna S, Basu AK, Verma K. Pulmonary coccidiomycosis in New Delhi, India. Infection. 2012;40(6):699-702.

92. Ogiso A, Ito M, Koyama M, Yamaoka H, Hotchi M, McGinnis MR. Pulmonary coccidioidomycosis in Japan: case report and review. Clin Infect Dis. 1997;25(5):1260-1.

93. Verghese S, Arjundas D, Krishnakumar KC, Padmaja P, Elizabeth D, Padhye AA, et al. Coccidioidomycosis in India: report of a second imported case. Med Mycol. 2002;40(3):307-9.

94. Jang J, Lee HJ, Lee I, Cho YK, Kim HJ, Sohn KH. The first imported case of pulmonary coccidioidomycosis in Korea. $\mathrm{J}$ Korean Med Sci. 1999;14(2):206-9.

95. Louie L, Ng S, Hajjeh R, Johnson R, Vugia D, Werner SB, et al. Influence of host genetics on the severity of coccidioidomycosis. Emerg Infect Dis. 1999;5(5):672-80.

96. McCotter O, Kennedy J, McCollum J, Bartholomew M, Iralu J, Jackson BR, et al. Coccidioidomycosis among American Indians and Alaska Natives, 2001-2014. Open Forum Infect Dis. 2019;6(3):ofz052. 
97. Ampel NM, Dols CL, Galgiani JN. Coccidioidomycosis during human immunodeficiency virus infection: results of a prospective study in a coccidioidal endemic area. Am J Med. 1993;94(3):23540.

98. Kirkland TN, Fierer J. Coccidioides immitis and posadasii; a review of their biology, genomics, pathogenesis, and host immunity. Virulence. 2018;9(1):1426-35.

99. Blair JE, Logan JL. Coccidioidomycosis in solid organ transplantation. Clin Infect Dis. 2001;33(9):1536-44.

100. Masannat FY, Ampel NM. Coccidioidomycosis in patients with HIV-1 infection in the era of potent antiretroviral therapy. Clin Infect Dis. 2010;50(1):1-7.

101. Bergstrom L, Yocum DE, Ampel NM, Villanueva I, Lisse J, Gluck $\mathrm{O}$, et al. Increased risk of coccidioidomycosis in patients treated with tumor necrosis factor alpha antagonists. Arthritis Rheum. 2004;50(6):1959-66.

102. Cole GT, et al. Isolation and morphology of an immunoreactive outer wall fraction produced by spherules of Coccidioides immitis. Infect Immun. 1988;56(10):2686-94.

103. Cole GT, Kirkland TN, Franco M, Zhu S, Yuan L, Sun SH, et al. Immunoreactivity of a surface wall fraction produced by spherules of Coccidioides immitis. Infect Immun. 1988;56(10):2695-701.

104. Hung CY, Ampel NM, Christian L, Seshan KR, Cole GT. A major cell surface antigen of Coccidioides immitis which elicits both humoral and cellular immune responses. Infect Immun. 2000;68(2):584-93.

105. Hung CY, Yu JJ, Seshan KR, Reichard U, Cole GT. A parasitic phase-specific adhesin of Coccidioides immitis contributes to the virulence of this respiratory fungal pathogen. Infect Immun. 2002;70(7):3443-56.

106. Hung CY, Xue J, Cole GT. Virulence mechanisms of coccidioides. Ann N Y Acad Sci. 2007;1111:225-35 This review discusses some of the key virulence mechanisms for coccidioidal infection that have been discovered such as production of SOWgp and its regulation at certain stages of infection.

107. Johannesson H, Townsend JP, Hung CY, Cole GT, Taylor JW. Concerted evolution in the repeats of an immunomodulating cell surface protein, SOWgp, of the human pathogenic fungi Coccidioides immitis and C. posadasii. Genetics. 2005;171(1): 109-17.

108. Perfect SE, O'Connell RJ, Green EF, Doering-Saad C, Green JR. Expression cloning of a fungal proline-rich glycoprotein specific to the biotrophic interface formed in the Colletotrichum-bean interaction. Plant J. 1998;15(2):273-9.

109. Staab JF, Bradway SD, Fidel PL, Sundstrom P. Adhesive and mammalian transglutaminase substrate properties of Candida albicans Hwp1. Science. 1999;283(5407):1535-8.

110. Brady LJ, Cvitkovitch DG, Geric CM, Addison MN, Joyce JC, Crowley PJ, et al. Deletion of the central proline-rich repeat domain results in altered antigenicity and lack of surface expression of the Streptococcus mutans P1 adhesin molecule. Infect Immun. 1998;66(9):4274-82.

111. Rawlings ND, Tolle DP, Barrett AJ. MEROPS: the peptidase database. Nucleic Acids Res. 2004;32(Database issue):D160-4.

112. Hung CY, Seshan KR, Yu JJ, Schaller R, Xue J, Basrur V, et al. A metalloproteinase of Coccidioides posadasii contributes to evasion of host detection. Infect Immun. 2005;73(10):6689-703.

113. Mirbod-Donovan F, Schaller R, Hung CY, Xue J, Reichard U, Cole GT. Urease produced by Coccidioides posadasii contributes to the virulence of this respiratory pathogen. Infect Immun. 2006;74(1):504-15.

114. Osterholzer JJ, Surana R, Milam JE, Montano GT, Chen GH, Sonstein J, et al. Cryptococcal urease promotes the accumulation of immature dendritic cells and a non-protective T2 immune response within the lung. Am J Pathol. 2009;174(3):932-43.
115. Mirbod F, Schaller RA, Cole GT. Purification and characterization of urease isolated from the pathogenic fungus Coccidioides immitis. Med Mycol. 2002;40(1):35-44.

116. Yu JJ, Smithson SL, Thomas PW, Kirkland TN, Cole GT. Isolation and characterization of the urease gene (URE) from the pathogenic fungus Coccidioides immitis. Gene. 1997;198(1-2): 387-91.

117. Mobley HL, Island MD, Hausinger RP. Molecular biology of microbial ureases. Microbiol Rev. 1995;59(3):451-80.

118. Burall LS, Harro JM, Li X, Lockatell CV, Himpsl SD, Hebel JR, et al. Proteus mirabilis genes that contribute to pathogenesis of urinary tract infection: identification of 25 signature-tagged mutants attenuated at least 100-fold. Infect Immun. 2004;72(5):292238.

119. Mobley HL. The role of Helicobacter pylori urease in the pathogenesis of gastritis and peptic ulceration. Aliment Pharmacol Ther. 1996;10(Suppl 1):57-64.

120. Wise HZ, Hung CY, Whiston E, Taylor JW, Cole GT. Extracellular ammonia at sites of pulmonary infection with Coccidioides posadasii contributes to severity of the respiratory disease. Microb Pathog. 2013;59-60:19-28.

121. Nosanchuk JD, Yu JJ, Hung CY, Casadevall A, Cole GT. Coccidioides posadasii produces melanin in vitro and during infection. Fungal Genet Biol. 2007;44(6):517-20.

122. Nosanchuk JD, Rosas AL, Lee SC, Casadevall A. Melanisation of Cryptococcus neoformans in human brain tissue. Lancet. 2000;355(9220):2049-50.

123. Rosas AL, Nosanchuk JD, Gómez BL, Edens WA, Henson JM, Casadevall A. Isolation and serological analyses of fungal melanins. J Immunol Methods. 2000;244(1-2):69-80.

124. Tsai HF, Fujii I, Watanabe A, Wheeler MH, Chang YC, Yasuoka $\mathrm{Y}$, et al. Pentaketide melanin biosynthesis in Aspergillus fumigatus requires chain-length shortening of a heptaketide precursor. J Biol Chem. 2001;276(31):29292-8.

125. Schnitzler N, et al. Effect of melanin and carotenoids of Exophiala (Wangiella) dermatitidis on phagocytosis, oxidative burst, and killing by human neutrophils. Infect Immun. 1999;67(1):94-101.

126. Romero-Martinez R, Wheeler M, Guerrero-Plata A, Rico G, Torres-Guerrero H. Biosynthesis and functions of melanin in Sporothrix schenckii. Infect Immun. 2000;68(6):3696-703.

127. Nosanchuk JD, Casadevall A. The contribution of melanin to microbial pathogenesis. Cell Microbiol. 2003;5(4):203-23.

128. Ampel NM, Giblin A, Mourani JP, Galgiani JN. Factors and outcomes associated with the decision to treat primary pulmonary coccidioidomycosis. Clin Infect Dis. 2009;48(2):172-8.

129. Blair JE, et al. Characteristics of patients with mild to moderate primary pulmonary coccidioidomycosis. Emerg Infect Dis. 2014;20(6):983-90.

130. Hector RF, Laniado-Laborin R. Coccidioidomycosis - a fungal disease of the Americas. PLoS Med. 2005;2(1):e2.

131. Galgiani JN, Ampel NM, Blair JE, Catanzaro A, Geertsma F, Hoover SE, et al. 2016 Infectious Diseases Society of America (IDSA) clinical practice guideline for the treatment of coccidioidomycosis. Clin Infect Dis. 2016;63(6):e112-46.

132. Pilmis B, et al. Antifungal drugs during pregnancy: an updated review. J Antimicrob Chemother. 2015;70(1):14-22.

133. Dewsnup DH, Galgiani JN, Graybill JR, Diaz M, Rendon A, Cloud GA, et al. Is it ever safe to stop azole therapy for Coccidioides immitis meningitis? Ann Intern Med. 1996;124(3): 305-10.

134.• Thompson GR 3rd, et al. Current concepts and future directions in the pharmacology and treatment of coccidioidomycosis. Med Mycol. 2019;57(Supplement_1):S76-84 This paper reviews the management of coccidioidomycosis with triazole and polyene therapy and highlights some potential theurapeutics in the development pipeline. 
135. Arndt CA, et al. Fluconazole penetration into cerebrospinal fluid: implications for treating fungal infections of the central nervous system. J Infect Dis. 1988;157(1):178-80.

136. Dodds Ashley ES, et al. Pharmacology of systemic antifungal agents. Clin Infect Dis. 2006;43:S28-39.

137. Thompson GR 3rd, Barker BM, Wiederhold NP. Large-scale evaluation of in vitro amphotericin B, triazole, and echinocandin activity against Coccidioides species from U.S. institutions. Antimicrob Agents Chemother. 2017;61(4).

138. Galgiani, J.N., et al., Comparison of oral fluconazole and itraconazole for progressive, nonmeningeal coccidioidomycosis. A randomized, double-blind trial. Mycoses Study Group. Ann Intern Med, 2000. 133(9): p. 676-686.

139. Saravolatz LD, Johnson LB, Kauffman CA. Voriconazole: a new triazole antifungal agent. Clin Infect Dis. 2003;36(5):630-7.

140. Cortez KJ, Walsh TJ, Bennett JE. Successful treatment of coccidioidal meningitis with voriconazole. Clin Infect Dis. 2003;36(12):1619-22.

141. Proia LA, Tenorio AR. Successful use of voriconazole for treatment of Coccidioides meningitis. Antimicrob Agents Chemother. 2004;48(6):2341.

142. Freifeld A, Proia L, Andes D, Baddour LM, Blair J, Spellberg B, et al. Voriconazole use for endemic fungal infections. Antimicrob Agents Chemother. 2009;53(4):1648-51.

143. Kim MM, Vikram HR, Kusne S, Seville MT, Blair JE. Treatment of refractory coccidioidomycosis with voriconazole or posaconazole. Clin Infect Dis. 2011;53(11):1060-6.

144. Gonzalez GM, Tijerina R, Najvar LK, Bocanegra R, Rinaldi M, Loebenberg $\mathrm{D}$, et al. In vitro and in vivo activities of posaconazole against Coccidioides immitis. Antimicrob Agents Chemother. 2002;46(5):1352-6.

145. Lutz JE, Clemons KV, Aristizabal BH, Stevens DA. Activity of the triazole SCH 56592 against disseminated murine coccidioidomycosis. Antimicrob Agents Chemother. 1997;41(7):1558-61.

146. Johnson RH, Einstein HE. Amphotericin B and coccidioidomycosis. Ann N Y Acad Sci. 2007;1111:434-41.

147. Seyedmousavi S, et al. Systemic antifungal agents: current status and projected future developments. Methods Mol Biol. 2017;1508:107-39.
148. Lindsay J, Sandaradura I, Wong K, Arthur C, Stevenson W, Kerridge I, et al. Serum levels, safety and tolerability of new formulation SUBA-itraconazole prophylaxis in patients with haematological malignancy or undergoing allogeneic stem cell transplantation. J Antimicrob Chemother. 2017;72(12):3414-9.

149. Wiederhold NP. Antifungal resistance: current trends and future strategies to combat. Infect Drug Resist. 2017;10:249-59.

150. Kong YC, Levine HB. Experimentally induced immunity in the mycoses. Bacteriol Rev. 1967;31(1):35-53.

151. Pappagianis D. Evaluation of the protective efficacy of the killed Coccidioides immitis spherule vaccine in humans. The Valley Fever Vaccine Study Group. Am Rev Respir Dis. 1993;148(3): 656-60.

152. Capilla J, Clemons KV, Liu M, Levine HB, Stevens DA. Saccharomyces cerevisiae as a vaccine against coccidioidomycosis. Vaccine. 2009;27(27):3662-8.

153. Zimmermann CR, Johnson SM, Martens GW, White AG, Zimmer BL, Pappagianis D. Protection against lethal murine coccidioidomycosis by a soluble vaccine from spherules. Infect Immun. 1998;66(5):2342-5.

154. Kirkland TN. The quest for a vaccine against coccidioidomycosis: a neglected disease of the Americas. J Fungi (Basel). 2016;2(4).

155. Xue J, et al. A genetically engineered live attenuated vaccine of Coccidioides posadasii protects $\mathrm{BALB} / \mathrm{c}$ mice against coccidioidomycosis. Infect Immun. 2009;77(8):3196-208.

156. Cole GT, Hung CY, Sanderson SD, Hurtgen BJ, Wüthrich M, Klein BS, et al. Novel strategies to enhance vaccine immunity against coccidioidomycosis. PLoS Pathog. 2013;9(12):e1003768.

157. McCotter OZ, Benedict K, Engelthaler DM, Komatsu K, Lucas $\mathrm{KD}$, Mohle-Boetani JC, et al. Update on the epidemiology of coccidioidomycosis in the United States. Med Mycol. 2019;57(Supplement 1):S30-40.

Publisher's Note Springer Nature remains neutral with regard to jurisdictional claims in published maps and institutional affiliations. 